\title{
Genetic analyses reveal population structure and recent decline in leopards (Panthera pardus fusca) across Indian subcontinent
}

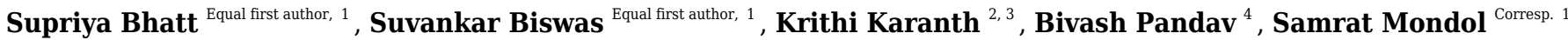 \\ ${ }^{1}$ Animal Ecology and Conservation Biology, Wildlife Institute of India, Dehradun, India \\ 2 Centre for Wildlife Studies, Bengaluru, India \\ 3 Nicholas School of Environment, Duke University, Durham, United States of America \\ 4 Endangered Species Management, Wildlife Institute of India, Dehradun, India \\ Corresponding Author: Samrat Mondol \\ Email address: samrat@wii.gov.in
}

\section{Background}

Large carnivores maintain the stability and functioning of ecosystems. Currently, many carnivore species face declining population sizes due to natural and anthropogenic pressures. The leopard, Panthera pardus, is probably the most widely distributed and highly adaptable large felid globally, still persisting in most of its historic range. However, we lack subspecies-level data on country or regional scale on population trends, as ecological monitoring approaches are difficult to apply on such wide-ranging species. We used genetic data from leopards sampled across the Indian subcontinent to investigate population structure and patterns of demographic decline.

\section{Methods}

We collected faecal samples from the Terai-Arc landscape of north India and identified 56 unique individuals using a panel of 13 microsatellite markers. We merged this data with already available 143 leopard individuals and assessed genetic structure at country scale. Subsequently, we investigated the demographic history of each identified subpopulations and compared genetic decline analyses with countrywide local extinction probabilities.

\section{Results}

Our genetic analyses revealed four distinct subpopulations corresponding to Western Ghats, Deccan Plateau-Semi Arid, Shivalik and Terai region of the north Indian landscape, each with high genetic variation. Coalescent simulations with microsatellite loci revealed a possibly human-induced $75-90 \%$ population decline between 120-200 years ago across India. Population-specific estimates of genetic decline are in concordance with ecological estimates of local extinction probabilities in these subpopulations obtained from occupancy modeling of the historic and current distribution of leopards in India.

\section{Conclusions}

Our results confirm the population decline of a widely distributed, adaptable large carnivore. We reiterate the relevance of indirect genetic methods for such species in conjunction with occupancy

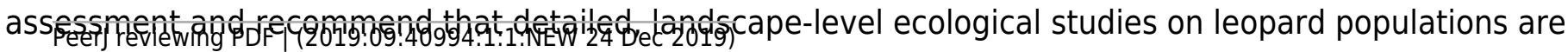


critical to future conservation efforts. Our approaches and inference are relevant to other widely distributed, seemingly unaffected carnivores such as the leopard. 
1 Title: Genetic analyses reveal population structure and recent decline in leopards

2 (Panthera pardus fusca) across Indian subcontinent

3

4 Supriya Bhatt $^{1 \#}$, Suvankar Biswas ${ }^{1 \#}$, Krithi K. Karanth ${ }^{2,3}$ Bivash Pandav $^{4}$, Samrat Mondol ${ }^{1 * \#}$

5

61 Animal Ecology and Conservation Biology, Wildlife Institute of India, Dehradun, India. ${ }^{2}$

7 Centre for Wildlife Studies, Bengaluru, Karnataka, India

$8{ }^{3}$ Nicholas School of Environment, Duke University, Durham, United States of America

$9{ }^{4}$ Endangered Species Management, Wildlife Institute of India, Dehradun, India.

$10 \quad$ \#Equal contributor

11

12 *Corresponding author: Samrat Mondol, Animal Ecology and Conservation Biology, Wildlife

13 Institute of India, Dehradun, India. Email- samrat@wii.gov.in

17 Running title: Population genetics and demography of Indian leopards 


\section{Abstract}

\section{Background}

23 Large carnivores maintain the stability and functioning of ecosystems. Currently, many carnivore

24 species face declining population sizes due to natural and anthropogenic pressures. The 25 leopard, Panthera pardus, is probably the most widely distributed and highly adaptable large 26 felid globally, still persisting in most of its historic range. However, we lack subspecies-level 27 data on country or regional scale on population trends, as ecological monitoring approaches are difficult to apply on such wide-ranging species. We used genetic data from leopards sampled across the Indian subcontinent to investigate population structure and patterns of demographic decline.

\section{Methods}

We collected faecal samples from the Terai-Arc landscape of north India and identified 56 unique individuals using a panel of 13 microsatellite markers. We merged this data with already available 143 leopard individuals and assessed genetic structure at country scale. Subsequently, we investigated the demographic history of each identified subpopulations and compared genetic decline analyses with countrywide local extinction probabilities.

\section{Results}

Our genetic analyses revealed four distinct subpopulations corresponding to Western Ghats, Deccan Plateau-Semi Arid, Shivalik and Terai region of the north Indian landscape, each with high genetic variation. Coalescent simulations with microsatellite loci revealed a possibly

41 human-induced $75-90 \%$ population decline between $\sim 120-200$ years ago across India. 
42 Population-specific estimates of genetic decline are in concordance with ecological estimates of

43 local extinction probabilities in these subpopulations obtained from occupancy modeling of the

44 historic and current distribution of leopards in India.

45 Conclusions

46 Our results confirm the population decline of a widely distributed, adaptable large carnivore. We

47 re-iterate the relevance of indirect genetic methods for such species in conjunction with

48 occupancy assessment and recommend that detailed, landscape-level ecological studies on

49 leopard populations are critical to future conservation efforts. Our approaches and inference are

50 relevant to other widely distributed, seemingly unaffected carnivores such as the leopard.

51

52

53

54

55

56

57

58

59

60

61

\section{Introduction}

63 Large carnivores are critical to ecosystem structure and functioning and their absence can lead to

64 significant changes in them and may affect trophic dynamics, resulting in cascading effects 
65 (Estes et al., 2011; Ripple et al., 2014). Growing natural and anthropogenic pressures in the form 66 of climate change, habitat loss and prey depletion, wildlife trade and human-wildlife conflicts are

67 pushing large carnivores into ever-shrinking habitat islands and severely exacerbating their 68 endangered status, and in some cases extinction (Schipper et al., 2008; Karanth et al., 2010). Recent assessments of the conservation status indicate alarming rates of population decline for many carnivores at a global scale. Specifically, the families Felidae, Canidae and Ursidae are under severe threat across the globe (Wolf \& Ripple, 2017). The leopard (Panthera pardus) represents the most widely distributed and adaptable member of the family Felidae. The historical range of leopards spanned across nearly 35,000,000 $\mathrm{km}^{2}$ area covering all of sub-Saharan and North Africa, the Middle East and Asia Minor, South and Southeast Asia, and the Russian Far East (Uphyrkina et al., 2001; Jacobson et al., 2016). However, their current distribution and numbers have significantly decreased across the range due to habitat loss, prey depletion, conflict and poaching over the last century (Jacobson et al., 2016). Recent meta-analyses of leopard status and distribution suggest $48-67 \%$ range loss for the species in Africa and 83-87\% in Asia (Jacobson et al., 2016), making them among the top ten large carnivore species most-affected by range contraction (Wolf and Ripple, 2017). This has resulted in changing the species status from 'Near Threatened' to 'Vulnerable' by IUCN (Stein et al., 2016). Despite continuously decreasing numbers and range, their ubiquitous presence across human habitations leads to misconceptions regarding their current abundance. Among all the subspecies, the Indian leopard ( $P$. p. fusca) retains the largest population size and range outside Africa (Jacobson et al., 2016). In the Indian subcontinent poaching and conflict are major threats to leopard populations (Athreya et al., 2010; Raza et al., 2012). Leopards also

87 frequently occur outside protected areas, increasing their vulnerability to conflict with humans 
88 (Athreya et al., 2010; Naha, Sathyakumar \& Rawat, 2018). Unfortunately, there is still a paucity

89 of information on their population and demography at regional and global scales. Few earlier

90 studies have assessed the subspecies status (Asad et al., 2019; Farhadinia et al., 2015; Paijmans

91 et al., 2018) and genetic diversity (Uphyrkina et al., 2001; Dutta et al., 2013; Mondol et al.,

92 2014) of leopards in the Asian region including India, but comprehensive data is lacking. Much

93 of our knowledge on leopard ecology and demography in the Indian subcontinent come from

94 location-specific studies (Karanth \& Sunquist, 2000; Chauhan et al., 2005; Harihar et al., 2009;

95 Wang and Macdonald, 2009; Kalle et al., 2011; Grant, 2012; Mondal et al., 2012; Dutta et al.,

96 2012, 2013; Thapa et al., 2014; Borah et al., 2014; Selvan et al., 2014; Pawar et al., 2019). In

97 India, the latest estimate of leopards in the forested habitats of 14 tiger-inhabiting states is 7910

98 (SE 6566-9181) (Jhala, Qureshi \& Gopal, 2015). As leopards do survive in highly human

99 populated and modified areas (Athreya et al., 2010) this estimate is likely to be minimal and

100 incomplete. Further, recent studies in the Indian subcontinent provide contradictory patterns of

101 local population trends. For example, historical records and occupancy estimation models based

102 on ecological data and field observations by Karanth et al. (2010) estimated high local extinction

103 probabilities of leopards across the subcontinent, and Athreya et al. (2010) reported higher rates

104 of recent conflict incidences and related mortality at local scales. Other ecological (Harihar,

105 Pandav \& Goyal, 2011) as well as population genetic studies of demographic history (Dutta et 106 al., 2013) suggest stable or increased leopard populations at a landscape scale. However, lack of 107 detailed, systematic field data makes it difficult to generate accurate population estimates as well 108 as demographic patterns at landscape scales.

109 In this paper, we used faecal samples to assess leopard genetic variation, population structure and 110 demographic history in the Indian subcontinent. More specifically, we investigated (1) extent of 
111 genetic variation in leopard that persists across the Indian subcontinent; (2) population structure

112 of leopards at country scale; (3) the demographic history of leopards by assessing recent changes

113 in population size and finally (4) compared the finding of genetic decline analyses with

114 countrywide local extinction probabilities. We interpreted our results in the context of local

115 extinction probabilities as estimated in Karanth et al. (2010). We addressed these questions using

116 genetic data generated using 13 polymorphic microsatellite loci from leopard faecal samples

117 collected across different landscapes of India.

118 Methods

119 Research permissions and ethical considerations

120 All required permissions for our field surveys and biological sampling were provided by the

121 Forest Departments of Uttarakhand (Permit no: 90/5-6), Uttar Pradesh (Permit no: 1127/23-2-

$12212(\mathrm{G})$ and 1891/23-2-12) and Bihar (Permit no: Wildlife-589). Due to non-invasive nature of

123 sampling, no ethical clearance was required for this study.

124 Sampling

125 To detect population structure and past population demography it is important to obtain genetic

126 samples from different leopard habitats all across the study area. In this study, we used leopard

127 genetic data generated from non-invasive samples collected across the Indian subcontinent. We

128 conducted extensive field surveys across the Indian part of Terai-Arc landscape (TAL) covering

129 the north-Indian states of Uttarakhand, Uttar Pradesh and Bihar between 2016-2018. This region

130 has already been studied for large carnivore occupancy using traditional camera trapping as well

131 as field surveys (Johnsingh et al., 2004; Harihar et al., 2009; Jhala et al., 2015; Chanchani et al.,

132 2016). We foot surveyed all existing trails covering the entire region to collect faecal samples.

133 Number of trails walked in a particular area was decided based on existing knowledge of leopard 
134 presence by the local people and frontline staff members of the sampling team. We collected a 135 total of 778 fresh large carnivore faecal samples. These samples were collected from both inside $136(n=469)$ and outside $(n=309)$ protected areas from different parts of this landscape. In the field, 137 the samples were judged as large carnivores based on several physical characteristics such as 138 scrape marks, tracks, faecal diameter etc. All faecal samples were collected in wax paper and 139 stored individually in sterile zip-lock bags and stored inside dry, dark boxes in the field for a 140 maximum of two weeks period (Biswas et al., 2019). All samples were collected with GPS 141 locations and were transferred to the laboratory and stored in $-20^{\circ} \mathrm{C}$ freezers until further 142 processing.

143 In addition to the north Indian samples collected in this study, we used genetic data previously 144 described in Mondol et al. (2015), representing mostly the Western Ghats and central Indian 145 landscape. The data was earlier used in forensic analyses to assign seized leopard samples to 146 their potential geographic origins in India (Mondol et al., 2015). Out of the 173 individual 147 leopards described in the earlier study, we removed data from related individuals and samples 148 with insufficient data $(n=30)$ and used the remaining 143 samples for analyses in this study. 149 These samples were collected from the states of Kerala ( $n=5)$, Tamil Nadu (n=4), Karnataka 150 ( $n=53)$, Andhra Pradesh $(n=3)$, Madhya Pradesh $(n=12)$, Maharashtra $(n=46)$, Gujarat $(n=2)$, 151 Rajasthan $(n=5)$, Himachal Pradesh $(n=8)$, Jharkhand $(n=1)$, West Bengal $(n=2)$ and Assam $152(\mathrm{n}=2)$, respectively. The sample locations are presented in Figure 1.

\section{DNA extraction, species and individual identification}

154 For all field-collected faecal samples, DNA extraction was performed using protocols described 155 in Biswas et al. (2019). In brief, each frozen faeces was thawed to room temperature and the 156 upper layer was swabbed twice with Phosphate buffer saline (PBS) saturated sterile cotton 
157 applicators (HiMedia). The swabs were lysed with $30 \mu \mathrm{l}$ of Proteinase K (20mg/ml) and $300 \mu \mathrm{l}$

158 of ATL buffer (Qiagen Inc., Hilden, Germany) overnight at $56^{\circ} \mathrm{C}$, followed by Qiagen DNeasy

159 tissue DNA kit extraction protocol. DNA was eluted twice in $100 \mu 1$ preheated $1 \mathrm{X}$ TE buffer. For

160 every set of samples, extraction negatives were included to monitor possible contaminations.

161 Species identification was performed using leopard-specific multiplex PCR assay with NADH4

162 and NADH2 region primers described in Mondol et al., (2014) and cytochrome b primers used in

163 Maroju et al., (2016). PCR reactions were done in $10 \mu 1$ volumes containing $3.5 \mu 1$ multiplex

164 buffer mix (Qiagen Inc., Hilden, Germany), $4 \mu \mathrm{M}$ BSA, $0.2 \mu \mathrm{M}$ primer mix and $3 \mu 1$ of scat

165 DNA with conditions including initial denaturation $\left(95^{\circ} \mathrm{C}\right.$ for $\left.15 \mathrm{~min}\right)$; 40 cycles of denaturation

$166\left(94^{\circ} \mathrm{C}\right.$ for $\left.30 \mathrm{~s}\right)$, annealing $\left(\mathrm{T}_{\mathrm{a}}\right.$ for $\left.30 \mathrm{~s}\right)$ and extension $\left(72^{\circ} \mathrm{C}\right.$ for $\left.35 \mathrm{~s}\right)$; followed by a final

167 extension $\left(72^{\circ} \mathrm{C}\right.$ for $\left.10 \mathrm{~min}\right)$. Negative controls were included to monitor possible contamination.

168 Leopard faeces were identified by viewing species-specific bands of 130 bp (NADH4) and 190

169 bp (NADH2) (Mondol et al., 2014) and 277 bp (cytochrome b) (Maroju et al., 2016) in 2\% 170 agarose gel.

171 For individual identification, we used the same panel of 13 microsatellite loci previously used in

172 Mondol et al. (2014) (Table 1). To generate comparable data with the samples used from earlier

173 study by Mondol et al. (2014) we employed stringent laboratory protocols. All PCR

174 amplifications were performed in $10 \mu \mathrm{l}$ volumes containing $5 \mu \mathrm{l}$ Qiagen multiplex PCR buffer

175 mix (QIAGEN Inc., Hilden, Germany), $0.2 \mu \mathrm{M}$ labelled forward primer (Applied Biosystems,

176 Foster City, CA, USA), $0.2 \mu \mathrm{M}$ unlabelled reverse primer, $4 \mu \mathrm{M}$ BSA and $3 \mu 1$ of the faecal

177 DNA extract. The reactions were performed in an ABI thermocycler with conditions including

178 initial denaturation $\left(94^{\circ} \mathrm{C}\right.$ for $\left.15 \mathrm{~min}\right) ; 45$ cycles of denaturation $\left(94^{\circ} \mathrm{C}\right.$ for $\left.30 \mathrm{sec}\right)$, annealing $\left(\mathrm{T}_{\mathrm{a}}\right.$

179 for $30 \mathrm{sec})$ and extension $\left(72^{\circ} \mathrm{C}\right.$ for $\left.30 \mathrm{sec}\right)$; followed by final extension $\left(72^{\circ} \mathrm{C}\right.$ for $\left.30 \mathrm{~min}\right)$. 
180 Multiple primers were multiplexed to reduce cost and save DNA (Table 1). PCR negatives were 181 incorporated in all reaction setups to monitor possible contamination. The PCR products were 182 analyzed using an automated ABI 3500XL Bioanalyzer with LIZ 500 size standard (Applied 183 Biosystems, Foster City, CA, USA) and alleles were scored with GENEMAPPER version 4.0 184 (Softgenetics Inc., State Collage, PA, USA). During data generation from field-collected samples 185 we used one reference sample (genotyped for all loci) from the earlier study for genotyping. As 186 the entire new data is generated along with the reference sample and the alleles were scored 187 along with the reference genotypes, the new data (allele scores) were comparable with earlier 188 data for analyses.

189 To ensure high quality multi-locus genotypes from faecal samples, we followed a modified 190 multiple-tube approach in combination with quality index analyses (Miquel et al., 2006) as 191 described previously for leopards by Mondol et al. (2009a, 2014). All faecal samples were 192 amplified and genotyped four independent times for all the loci. Samples producing identical 193 genotypes for at least three independent amplifications (or a quality index of 0.75 or more) for 194 each loci were considered reliable and used for all further analysis, while the rest were discarded. 195 Analysis

196 For each locus, we calculated average amplification success as the percent positive PCR 197 (Broquet \& Petit, 2004) after four repeats across all samples. We quantified allelic dropout and 198 false allele rates manually as the number of dropouts or false alleles over the total number of 199 amplifications, respectively (Broquet \& Petit, 2004), as well as using MICROCHECKER v 200 2.2.3. (Van Oosterhout et al., 2004). The false allele frequency is calculated for both 201 homozygous and heterozygous genotypes as the ratio of the number of amplifications having one 202 or more false alleles at a particular locus and the total number of amplifications while allele 
203 dropout rate (ADO) is calculated as the ratio between the observed number of amplifications

204 having loss of one allele and the number of positive amplifications of heterozygous individuals.

205 Post data quality assessment we selected only those samples with good quality data for at least

206 nine or more loci (out of 13) for further analyses. We used the identity analysis module

207 implemented in program CERVUS (Kalinowski, Taper \& Marshall, 2007) to identify identical

208 genotypes (or recaptures) by comparing data from all samples. All genetic recaptures were

209 removed from the data set. GIMLET (Valiere, 2002) was used to calculate the PID $_{(\text {sibs }}$ for all the

210 unique individuals. Following this, any allele having less than $10 \%$ frequency across all

211 amplified samples were rechecked for allele confirmation. ARLEQUIN (Excoffier, Laval \&

212 Schneider, 2005) was used to determine Hardy Weinberg equilibrium and linkage disequilibrium

213 for all the loci. Finally, to avoid the effects of related individuals in all analyses, we used the

214 program GENECLASS 2.0 (Piry et al., 2004) to select out related individuals in our samples.

215 To determine the genetic structure of leopards across the Indian subcontinent we used a Bayesian

216 clustering approach implemented in program STRUCTURE (Pritchard, Stephens \& Donnelly,

217 2000; Falush, Stephens \& Pritchard, 2003). We performed 10 independent analyses for each K

218 values between one and ten, using 450,000 iterations and a burn-in of 50,000 assuming

219 correlated allele frequencies. The optimal value of $\mathrm{K}$ was determined using STRUCTURE

220 HARVESTER web version (Earl \& vonHoldt, 2012). Further, we used multivariate analyses

221 approach implemented in program Discriminant Analysis of Principal Component (DAPC)

222 (Jombart et al., 2010) to identify genetic clusters in our data. This approach transforms the

223 genetic data into principal components, followed by clustering to define group of individuals

224 with a consideration of minimum within group variation and maximum between group variations

225 among the clusters. The analyses were conducted using adegenet package 2.1 .1 in $\mathrm{R}$ studio 
226 1.1.453 (R Development Core Team 2018) where optimal number of clusters were determined

227 through the Bayesian Information Criterion (Jombart et al., 2010). Subsequent summary statistics

228 were calculated in ARLEQUIN 3.1 (Excoffier, Laval \& Schneider, 2005) and indices of overall

229 genetic differentiation (pairwise $\mathrm{F}_{\mathrm{st}}$ ) were estimated using GenAlEx version 6.5 (Peakall \&

230 Smouse, 2012), dividing the leopard populations according to the STRUCTURE results across

231 the Indian subcontinent. The divisions were based on Q-values (estimated proportions of 232 ancestry) calculated in STRUCTURE, where we used Q $>0.75$ as threshold for assigning 233 individuals to a particular population (Mora et al., 2010). Additionally, compression of expected

234 heterozygosity (or $\mathrm{G}_{\mathrm{st}}$ ) (Nei, 1973) between four leopard sub-populations was calculated in 235 GenAlEx version 6.5 (Peakall \& Smouse, 2012). Finally, HP-RARE 1.0 (Kalinowski, 2005) was 236 used to estimate private alleles within each subpopulation.

\section{Demography analyses}

238 Demographic analyses were performed with different genetic subpopulations of leopards based 239 on the results from STRUCTURE analyses. We used a number of different approaches to detect 240 past population demography for leopards. The first two qualitative approaches use summary 241 statistics to detect population size changes, whereas the quantitative approach is a likelihood242 based Bayesian algorithm. The summary statistic-based methods used were the Ewens, 243 Watterson, Cornuet and Luikart method implemented in program BOTTLENECK (Cournet \& 244 Luikart, 1996), and the Garza-Williamson index or M ratio (Garza \& Williamson, 2001) 245 implemented in program ARLEQUIN 3.1. The quantitative Bayesian approach used was 246 implemented in the program MSVAR 1.3 (Storz \& Beaumont, 2002).

247 a) The Ewens, Watterson, Cornuet and Luikart (EWCL) approach: 
248 This approach allows the detection of population size changes using two summary statistics of

249 the allele frequency spectrum, number of alleles $\left(\mathrm{N}_{\mathrm{A}}\right)$ and expected heterozygosity $\left(\mathrm{H}_{\mathrm{e}}\right)$ across

250 different mutational models. Simulations are performed to obtain the expected distribution of $\mathrm{H}_{\mathrm{e}}$

251 for a demographically stable population under three mutation models: infinite allele model

252 (IAM), single stepwise model (SMM) and two-phase model (TPM) and the values are then

253 compared to the real data values. This method can detect departures from mutation-drift

254 equilibrium and neutrality, which can be explained by any departure from the null model,

255 including selection, population growth or decline. More importantly, consistent results from

256 independent loci could be attributed to demographic events over selection. For simulations with

257 TPM model, we used two different (5\% and 30\%) multi-step mutation events for leopards.

258 b) The Garza-Williamson index/M ratio approach:

259 This approach allows the detection of population decline using two summary statistics of the

260 allele frequency spectrum, number of alleles $\left(\mathrm{N}_{\mathrm{A}}\right)$ and the allelic size range. The basic principle

261 behind this approach is in a reducing population, the expectation of the reduction of number of

262 alleles is much higher than the reduction of allelic size range. Thus, the ratio between the number

263 of alleles and the allelic size range is expected to be smaller in recently reduced populations than

264 in equilibrium populations.

265 c) The Storz and Beaumont approach:

266 This approach is an extension of Beaumont's approach (Beaumont, 1999) that assumes a stable

267 population of size $\mathrm{N}_{1}$ started to change (either decrease or increase) $\mathrm{T}_{\text {a }}$ generations ago to the

268 current population size $\mathrm{N}_{0}$. This change in the population size is assumed to be at an exponential

269 scale under stepwise mutation model $(\mathrm{SMM})$, at a rate $\mathrm{y}=2 \mathrm{~N}_{0} \mathrm{~m}$, where $\mathrm{m}$ is the mutation rate per

270 locus per generation. This Bayesian approach uses the information from the full allelic 
271 distribution in a coalescent framework to estimate the posterior probability distribution, allowing

272 quantification of effective population sizes $\mathrm{N}_{0}$ and $\mathrm{N}_{1}$, rather than their ratio (as in Beaumont

273 1999) along with $\mathrm{T}$, time since the population change. In this approach, prior distributions for $\mathrm{N}_{0}$,

$274 \mathrm{~N}_{1}$, T and $\mu$ (mutation rate) are assumed to be log normal. The mean and the standard deviations

275 of these prior log normal distributions are drawn from prior (or hyperpriors) distributions. A

276 Markov Chain Monte Carlo (MCMC) algorithm is used to generate samples from the posterior

277 distribution of these parameters. We used wide uninformative priors to perform multiple runs for

278 this approach (Supplementary Table 1). For minimal effect towards the posterior distributions

279 variances for the prior distributions were kept large. A total number of 2 million iterations were

280 performed for each run.

281 The generation time for leopards are known to be about 4-5 years (Dutta et al., 2013) and we

282 used a five-year generation time for all analyses.

\section{Estimation of leopard extinction probability}

284 To understand extinction probability across various biogeographic zones of India we analysed

285 patterns and determinants of leopard occurrence as described in Karanth et al. (2009, 2010). In

286 this study, we have just divided the earlier information available for leopards for different

287 genetic subpopulations. We applied a grid-based approach to determine current distribution

288 patterns for leopards, where the selection of grids was based on prior information of leopard

289 presence. This involved collating presence-absence information from more than 100 Indian

290 wildlife experts along with historical information of leopard presence involving hunting

291 locations and other taxidermy and museum records. Each grid cell was an average of $2818 \mathrm{~km}^{2}$

292 in size and we used data from 1229 grid cells covering 3,463,322 $\mathrm{km}^{2}$ area of the Indian

293 subcontinent. This study applied occupancy modelling to examine the influence of ecological 
294 and social covariates on patterns of leopard occupancy. We used a maximum likelihood 295 approach for leopard occupancy in PRESENCE. V.2.0 program (Hines, 2006). Covariates likely 296 to influence leopard distribution modelled included presence and extent of protected areas, land 297 cover-land use characteristics, human cultural tolerance and population density. Data for 298 protected areas was retrieved from the World Database on protected areas (www.unep299 wcmc.org) and topographic maps. Land cover- land use data were derived from Global Land 300 Cover Facility (2000) and further refined based on Roy et al. (2006) and Joshi et al. (2006). A 301 human tolerance index that characterized different Indian states from most to least tolerant was 302 developed based on knowledge about society-culture, law enforcement, hunting patterns and 303 prior field experiences (for details see Karanth et al. 2009, 2010). Human population density data 304 were derived from LandScan Global Population Data 2000 (www.ornl.gov/gist). Based on 305 existing information on species' ecology we predicted higher occupancy in protected areas, 306 deciduous-grass-scrub land cover types and lower occupancy in less tolerant states and highly 307 populated areas because of direct competition for food and space (Brashares, Arcese \& Sam, 308 2001; Rangarajan, 2001; Parks \& Harcourt, 2002; Karanth et al., 2010). We performed pair-wise 309 correlation tests to screen variables for multicollinearity. The occupancy approach accounts for non-detection of species during surveys and inability to survey some sites (see Karanth et al.,

3112009,2010 for additional details). The probability of extinction was calculated as (1- probability 312 of occurrence) (Karanth et al., 2010). We derived leopard extinction probabilities for three 313 separate major landscapes (Western Ghats, Central India and North India) as these regions 314 strongly represented our genetic sampling. These extinction probabilities were compared to the 315 genetically derived estimates.

\section{Results}




\section{Individual identification of leopards from north Indian landscape}

318 Of the 778 large carnivore faecal samples collected from TAL, we identified 195 faeces to be of

319 leopard origin (25\%) using species-specific PCR assays (Mondol et al., 2014; Maroju et al., 320 2016). In addition, 457 samples were ascertained to be of tiger (59\%) and remaining 126 faecal

321 samples did not produce any result (16\%) for either of these large felids, possibly due to poor

322 quality DNA. We amplified 13 microsatellite loci panel on these 195 genetically confirmed 323 leopard faecal samples, and after data validation through multiple repeats generated seven or 324 more loci data from 65 faecal DNA. Subsequently, we identified 56 unique leopard individuals 325 from the 65 samples, whereas nine individuals were ascertained as 'genetic recaptures'. The mean allelic dropout rate for these loci was found to be 0.05 , whereas mean false allele rate for

327 all the 13 loci was 0.04, indicating this 13 loci panel has low genotyping error rates. 328 Amplification success ranged between 41-100\% from leopard faecal DNA. None of the loci were 329 found to deviate from the Hardy-Weinberg equilibrium and there were no evidence for strong 330 linkage disequilibrium between any pair of loci. Cumulative PID $_{\text {sibs }}$ and PID $_{\text {unbiased values were }}$ 331 found to be $3.91 * 10^{-6}$ and $2.73 * 10^{-16}$, respectively, indicating a strong statistical support for unambiguous individual identification. Summary statistics for these samples collected across Terai-Arc landscape is provided in Table 1. We identified 26, 21 and nine unique leopard individuals from the states of Uttarakhand, Uttar Pradesh and Bihar, respectively. As the data data to 143 individual genotypes described in Mondol et al. (2014), and overall 199 unique

337 unrelated leopards were used in subsequent population structure, genetic variation and 338 demography analyses.

\section{Leopard population structure and genetic variation across India}


340 Our sampling strategy targeted countrywide leopard populations to assess population structure

341 and genetic variation. From 199 final unique leopard genotypes we removed four samples

342 representing the eastern and northeast India $(n=2$ from the states of West Bengal and Assam

343 each, respectively) from further analyses as they represented inadequate sampling from these

344 regions. Bayesian clustering analysis using 13 microsatellite data from the remaining 195 wild

345 leopard individuals showed four distinct genetic subpopulations ( $K=4$, see Supplementary Figure

346 1), as presented in Figure 1. The DAPC analyses identified five different clusters $(\mathrm{K}=5)$ using the

347 Bayesian Information Criterion (Supplementary Figure 2). However, out of these genetic clusters

348 two of them were overlapping with each other. Overall, both analyses showed the same pattern

349 of four genetic subpopulations. Majority of the samples showed respective group-specific

350 ancestry, with Western Ghats samples representing the first group (henceforth WG, $\mathrm{n}=65$ ), the

351 Deccan Plateau-Semi Arid region forming the second (henceforth DP-SA, n=66), the samples

352 from Shivalik region covering parts of Himalaya and western parts of upper Gangetic plains

353 making the third group (henceforth $\mathrm{SR}, \mathrm{n}=38$ ), and finally samples from the Terai region

354 covering eastern part of upper and western part of the lower Gangetic Plains samples forming the

355 fourth one (henceforth TR, $\mathrm{n}=26$ ), respectively (Figure 1). However, small number of samples

$356(n=18)$ distributed among the four subpopulations showed mixed ancestry. Subsequent analyses

357 revealed that these leopard subpopulations are genetically differentiated $\left(\mathrm{F}_{\mathrm{st}}\right.$ and $\left.\mathrm{G}_{\mathrm{st}}\right)$ at low, but

358 significant levels (Table 2) for all four populations. The $\mathrm{F}_{\text {st }}$ value among these populations

359 ranged between 0.028-0.115, whereas the $\mathrm{G}_{\mathrm{st}}$ value between 0.023-0.104 (Table 2).

360 Analyses and with 13 microsatellite loci among the four genetic subpopulations showed a higher

361 mean number of alleles $\left(\mathrm{NA}_{\mathrm{WG}}=11.77\right.$ (S.D. 3.85), $\mathrm{NA}_{\mathrm{DP}-\mathrm{SA}}=10.46$ (S.D. 2.71)) and observed

362 heterozygosity $\left(\mathrm{H}_{\mathrm{oWG}}=0.81\right.$ (S.D. 0.08), $\mathrm{H}_{\mathrm{oDP}-\mathrm{SA}}=0.8$ (S.D. 0.08)) in Western Ghats and Deccan 
363 Plateau-Semi Arid subpopulations, when compared with samples from Shivalik and Terai region

364 subpopulations $\left(\mathrm{NA}_{\mathrm{SR}}=08.46\right.$ (S.D. 2.41), $\mathrm{NA}_{\mathrm{TR}}=05.00$ (S.D. 1.84) and $\mathrm{H}_{\mathrm{OSR}}=0.40$ (S.D. 0.14),

$365 \mathrm{H}_{\mathrm{OTR}}=0.36$ (S.D. 0.28), respectively) (see Table 3 for details). However, the allelic size range

366 values were similar in all populations (Table 3). Western Ghats and Deccan Plateau- Semi Arid

367 subpopulations showed higher number of private alleles (2.38 and 0.85 , respectively) when

368 compared to Shivalik and Terai subpopulations ( 0.46 and 0.15 , respectively) (Table 3$)$.

\section{Detection of demographic change}

370 We used microsatellite data to investigate signals of demographic changes in each of the four 371 leopard genetic subpopulations across the subcontinent. Both qualitative approaches, the EWCL

372 and the M-ratio methods indicate signatures of population bottleneck. The EWCL approach

373 implemented in the program BOTTLENECK shows 8-10 loci with heterozygote excess 374 depending on the mutation models used, suggesting a loss of rare alleles through population 375 decline for all four subpopulations. Similarly, the M-ratio approach also shows a low ratio 376 between number of alleles $\left(\mathrm{N}_{\mathrm{A}}\right)$ and the allelic size range in all four populations (M-ratio $\mathrm{WG}^{-} 0.37$

377 (S.D. 0.09); M-ratio ${ }_{\mathrm{DP}-\mathrm{SA}^{-}} 0.38$ (S.D. 0.09); M-ratio $\mathrm{SR}^{-} 0.33$ (S.D. 0.09); M-ratio $\mathrm{TR}^{-} 0.29$ (S.D.

378 0.15)), indicating signatures of population bottleneck.

379 In the quantitative MSVAR approach, models with exponential decline scenarios show 380 consistently that the posterior distributions for $\log (\mathrm{N} 0)$ is always lower than $\log (\mathrm{N} 1)$ for all four 381 subpopulations, indicating population decline for leopards across the subcontinent (Table 4 and 382 Figure 2). Further quantification revealed that the current effective size is varyingly low (12$38325 \%$ ) than the historical effective size, with Western Ghats, Deccan Plateau-Semi Arid, Shivalik 384 and Terai regions losing approximately $75 \%, 90 \%, 90 \%$ and $88 \%$ of their leopard population, 385 respectively (Table 4 and Figure 2). 
386 Our subsequent analyses also revealed distributions that suggested recent time of declines in all 387 four populations of leopards (Table 4, Figure 2). The north Indian subpopulations (Shivalik and 388 Terai) and the Deccan Plateau-Semi Arid population showed the most recent decline occurred 389 about 120-125 years before present, respectively. However, the Western Ghats population 390 indicated potential decline around 200 years ago (Table 4 and Figure 2).

\section{Leopard occurrence and distribution}

392 We examined the factors influencing leopard distribution at a countrywide scale, where the top 393 ranked model incorporating 28 covariates suggested a wide distribution of habitat types 394 (described in Karanth et al., 2009, 2010). The model also indicated a positive influence of 395 protected areas, higher cultural tolerance of people and negative influence of higher human 396 population densities and (details in Karanth et al., 2009). Areas with cultivated land, barren 397 areas, deciduous forests and rural-urban were strongly associated with higher leopard occurrence. Naive estimated occupancy was 0.52 , whereas model estimated probability of 399 occupancy was significantly higher at 0.68 , suggesting that leopards are still widely distributed (Figure 3) in India compared to most other large mammals (as suggested in Karanth et al., 2010). When compared among the overall three major sub-regions (North India (NI), Deccan PlateauSemi Arid and Western Ghats), we find that average estimated occurrence was lowest in the

403 North India ( $\mathrm{Psi}_{\mathrm{NI}}=0.63 \pm 0.01$, Range: $0.05-1.00,384$ cells) compared to Western Ghats $404\left(\mathrm{Psi}_{\mathrm{WG}}=0.83 \pm 0.02\right.$, Range: 0.23-1.00, 90 cells) and Deccan Plateau-Semi Arid (Psi $\mathrm{DP}_{\mathrm{DP}}$ $405 \mathrm{SA}=0.79 \pm 0.005$, Range:0.25-1.00, 818 cells). Overall, average estimated Psi was $0.74 \pm 0.006$ 406 (1292 cells).

\section{Discussion}


408 To the best of our knowledge, this is probably the first and most exhaustive study on leopard 409 population genetics and demographic patterns in the Indian subcontinent. Except the eastern and 410 northeast Indian landscape, where our sampling intensity was less all other regions are well 411 covered in this study. Our genetic analyses with microsatellite data collected across the 412 subcontinent reveal four genetic subpopulations of leopards in India: the Western Ghats, Deccan 413 Plateau-Semi Arid landscape, hill region of north India (Shivalik) and Terai or flat region of 414 north India. While there was some amount of mixed genetic signal across different genetic 415 subpopulations, they were clearly separated as different groups (Figure 1). These genetic groups 416 mostly correspond to respective biogeographic zones of India, with Western Ghats and 417 combination of Deccan Plateau-Semi Arid forms two subpopulations, whereas the north Indian 418 subpopulation of Shivalik and Terai are parts of the Himalayan and Gangetic Plains zones, 419 respectively.

420 Based on these patterns, we presume that these genetic clusters were formed due to restricted 421 gene flow along major habitat type differences between these biogeographic zones. For example, 422 the difference between habitat types of large contiguously forested Western Ghats (largely moist 423 deciduous habitat) and the Deccan Plateau-Semi Arid (mostly dry deciduous habitat) probably 424 lead to genetic differences between leopards from these regions. Similarly, difference in habitat 425 types in 'Bhabar' habitats of Shivalik (hilly rugged terrains, large trees, high leopard abundance) 426 and Terai region (flat terrain, grassland, low leopard abundance) (Johnsingh et al., 2004), has 427 possibly led to reduced gene flow between these two areas. Such habitat-driven reasons 428 meaningfully explain the genetic differentiation between leopards from these landscapes. These 429 four subpopulations were genetically differentiated by low, but significant levels (Table 2). 430 Previous studies on tigers (Mondol et al., 2009b, 2013 subcontinent scale) as well as leopards 
431 (Dutta et al., 2013, central Indian landscape) suggested long-distance movement as a potential 432 cause for low genetic differentiation between populations. Leopards are known to disperse long 433 distances (Ropiquet et al., 2015; Farhadinia et al., 2018) and human-leopard conflict driven 434 translocation is common in many parts in India (Athreya et al., 2010; Odden et al., 2014). 435 Together, natural dispersal abilities and 'human mediated gene flow' through translocations 436 might be responsible for the low genetic differentiation among leopard subpopulations across the 437 subcontinent. Earlier work in central Indian landscape (Dutta et al., 2013) suggested a reduction 438 in gene flow at recent times due to habitat destruction, but our study did not focus to answer such 439 questions. Future studies should focus on using historical samples (museum skins, bones etc.) to assess any possible change in gene flow among leopard populations (For example see Martinez-

441 Cruz et al., 2007; Valdiosera et al., 2008; Lorenzen et al., 2011; Mondol et al., 2013) at 442 subpopulation levels across the country.

443 However, our demography analyses with genetic data indicate strong decline in leopard 444 population size across all four genetic subpopulations. Results with both qualitative (bottleneck and M-ratio approach) as well as quantitative (Storz and Beaumont approach) analyses revealed 446 strong, but varying signals of demographic decline in all four subpopulations (Table 4). The 447 Deccan Plateau-Semi Arid, Shivalik and Terai subpopulations show 90\%, 90\% and 88\% decline 448 in population size, respectively, whereas the Western Ghats subpopulation show relatively less $449(75 \%)$ decline in population size (Table 4). Leopards are vulnerable to conflict and poaching due 450 to their close associations with human habitations (Gavashelishvili \& Lukarevshiy, 2008; 451 Athreya et al., 2010; Balme, Slotow \& Hunter, 2009). The Western Ghats retains possibly the 452 largest contiguous forested landscape with multiple interconnected protected areas, whereas the 453 other regions have lot of human activities, possibly affecting leopard populations living in them. 
454 Further, the ecological data based occupancy analysis showed extinction probabilities of 0.37 ,

4550.21 and 0.17 for North India, Deccan Plateau-Semi Arid and Western Ghats landscape, 456 respectively (Table 4). It is possible that this discrepancy in the magnitudes of decline based on 457 genetic and ecological models is because the ecological methods are more spatial. The inferences 458 from this model are dependent on temporal differences in leopard occupancy. However, if 459 densities of leopards were high in the past, loss of even small habitats could result in the loss of 460 many individuals. Since no quantitative comparisons for leopard density between the Western 461 Ghats, Deccan Plateau-Semi Arid and North India is currently available, we cannot conclusively 462 infer the former, but further research should investigate leopard densities and their temporal 463 changes across the country. Finally, this decline pattern also roughly corroborates with $83-87 \%$ 464 leopard range loss in Asia (Jacobson et al., 2016), indicating that habitat loss is a contributing 465 factor towards the population decline.

466 The magnitude of decline for leopards found in this study is contrasting to some of the earlier 467 leopard studies in the subcontinent (for example ecological work by Harihar et al., 2011, and 468 genetic work by Dutta et al., 2013) and eastern Africa (Spong, Johansson \& Bjorklund, 2000 in 469 Tanzania), which suggest stable or increasing local leopard population trends. This is certainly 470 possible as many of these studies were conducted inside protected areas, where leopard 471 population dynamics depends on presence/absence of other large carnivores (tiger, dhole etc.). 472 Given that only $11 \%$ of Indian leopard distribution is within protected area network (Jacobson et 473 al., 2016), it is challenging to truly understand the population trends at country level. Our 474 sampling at subcontinent scale is thus indicating the actual patterns of population demography 475 that is difficult to assess based on ecological/genetic studies at local level. 
476 Another important finding is the relatively recent timing of decline for all the leopard

477 subpopulations in the subcontinent. Our results suggest median leopard decline timing between

478 120-200 years across four genetic subpopulations (Table 4). Except Western Ghats (decline

479 timing of $\sim 200$ years), all other subpopulations indicate much recent population decline (Central

480 India-Deccan Plateau $\sim 125$ years, Shivalik $\sim 120$ years and Terai $\sim 125$ years). When compared

481 with other sympatric, endangered species in the subcontinent (for example tiger decline $~ 200$

482 years ago; Mondol et al., 2009b) or Asian region (for example Orangutan- 210 years, Goossens

483 et al., 2006; Giant panda- 250 years, Zhu et al., 2010) this still seems to be much recent event.

484 Other wide-ranging carnivores across the globe (for example European wolves Aspi et al., 2006;

485 African wild dog- Marsden et al., 2012; Eurasian badgers- Frantz et al., 2014 etc.) too faced

486 much longer decline period than leopards. One plausible explanation could be recent increases in

487 leopard-human conflict (Athreya et al., 2010; Karanth \& Kudalkar, 2017) and poaching intensity

488 due to large demand of leopard body parts in the illegal wildlife markets (Raza et al., 2012;

489 WPSI, 2017). Historically, major leopard hunting events had been recorded across the Indian

490 subcontinent during Mughal times (about 500-600 years ago), followed by colonial British

491 bounty-hunting rule between 1850-1920 (Rangarajan, 2005). However, large-scale landscape

492 modification and fragmentation by humans during the last century (central India- Rangarajan,

493 1999, north India- Rangarajan, 2005), coupled with poaching and conflict may have resulted in

494 much recent loss of leopard populations across the country. We lack comprehensive data, both at

495 historical as well as modern scales to investigate the true causes behind such patterns of

496 differential population decline timing. For example, Dutta et al. (2013) showed that during last

497 three centuries severe changes in landscape characteristics (Settlement, villages, wild lands,

498 human density) have occurred in the central Indian leopard habitats. However, we lack 
499 information on hunting and conflict levels during this time from these regions. Future efforts

500 should generate this important information to get an idea of the scenarios leading to such strong

501 decline in a wide-ranging species like leopard. Finally, it is important to point out that in this

502 study we have only explored relatively simple decline scenarios during demographic modelling.

503 Future studies should evaluate more detailed, computationally intensive demographic analyses

504 with genome wide molecular markers (For example, see Frantz et al., 2014; Nater et al., 2015)

505 for better understanding of complex decline scenarios.

506 Finally, another important aspect of the results from this study is that despite severe decline

507 (Table 4) and small, but significant population structure (Figure 1B, Table 2) leopards still retain

508 high genetic variation in the Indian subcontinent. We found that leopard genetic variation across

509 four genetic subpopulations is similar and comparable to eastern and southern Africa (Spong,

510 Johansson \& Bjorklund, 2000; Uphyrkina et al., 2001; McManus et al., 2015), and higher than

511 Arabian (Ilani, 1981; Perez et al., 2006) and Amur leopards (Uphyrkina et al., 2001; Sugimoto et

512 al., 2014). The higher levels of variation could possibly be attributed to still relatively large

513 population size, high pre-bottleneck genetic variation and potential historical gene flow across

514 large landscapes.

\section{Conclusion}

516 While leopards are relatively easier to study than other sympatric carnivores like tigers due to

517 their ubiquitous presence, studies on their population size, trend and dynamics are limited,

518 particularly in outside protected areas. In fact, due to their broad geographic distribution, leopard 519 populations are perceived to be stable, with current IUCN Red List status of 'vulnerable'.

520 However, both historical records and recent conflict with humans suggest potentially declining

521 population trends. Using genetic data, we reveal a strong signal of population decline (between 
$52275-90 \%$ ) across different habitats in the Indian subcontinent over the last 120-200 years. We

523 demonstrate population decline in a wide-ranging and, commonly perceived as locally abundant

524 species like the leopard, suggesting that leopards demand similar conservation attention like

525 tigers in India. While we are unable to corroborate these population decline patterns with leopard

526 census data, our results suggest that it will be important to generate such ecological abundance

527 estimates for leopard populations in the near future. This work also emphasizes the importance

528 of similar work on wide-ranging species, as it is possible that other species like the leopard may

529 show population declines, especially in the context of the Anthropocene.

530 Acknowledgement:

531 We acknowledge the Director, Dean and Nodal Officer of Wildlife Forensics and Conservation

532 Genetics Cell of Wildlife Institute of India for their support in this work. Our sincere thanks to 533 Forest Departments of Uttarakhand, Uttar Pradesh and Bihar for research permits. We thank Dr.

534 Uma Ramakrishnan of National Centre for Biological Sciences for providing reference leopard 535 samples. Mr A. Madhanraj has provided critical support in genotyping facility and Mr. Debanjan 536 Sarkar helped with GIS in the laboratory. We thank all the lab members of Wildlife Forensic and 537 Conservation Genetics cell and especially Meercat lab for productive discussions and valuable 538 comments. We also thank Dr. S. K. Gupta and Dr. S. P. Goyal for logistic support; our field 539 assistants Annu, Bura, Abbhi, Ranjhu and Imam for their effort in the field. Finally, we thank 540 two reviewers and the editor for their critical suggestions to improve our earlier version of the 541 manuscript.

542 References: 
543 Asad M, Martoni F, Ross JG, Waseem M, Paterson, AM. 2019. Assessing subspecies status of $544 \quad$ leopards (Panthera pardus) of northern Pakistan using mitochondrial DNA. PeerJ, 7:e7243. 545 DOI: $10.7717 /$ peerj. 7243.

546

547

548

549

550

551

552

553

554

555

556

557

558

559

560

561

562

563

Aspi J, Roininen E, Ruokonen M, Kojola I, Vila C. 2006. Genetic diversity, population structure, effective population size and demographic history of the Finnish wolf population. Molecular Ecology 15:1561-1576. DOI: 10.1111/j.1365-294X.2006.02877.x.

Athreya V, Odden M, Linnell JDC, Karanth KU. 2010. Translocation as a Tool for Mitigating Conflict with Leopards in Human-Dominated Landscapes of India. Conservation Biology 25:133-141. DOI: 10.1111/j.1523-1739.2010.01599.x.

Balme GA, Slotow R, Hunter LTB. 2009. Impact of conservation interventions on the dynamics and persistence of a persecuted leopard (Panthera pardus) population. Biological Conservation 142:2681-2690. DOI: 10.1016/j.biocon.2009.06.020.

Beaumont MA. 1999. Detecting population expansion and decline using microsatellites. Genetics 153:2013-2029.

Biswas S, Bhatt S, Paul S, Modi S, Ghosh T, Habib B, Nigam P, Talukdar G, Pandav B, Mondol S. 2019. A practive faeces collection protocol for multidisciplinary research in wildlife science. Current Science 116:1878-1885. DOI: 10.18520/cs/v116/i11/1878-1885.

Borah J, Sharma T, Das D, Rabha N, Kakati N, Basumatary A, Ahmed MF, Vattakaven J. 2014. Abundance and density estimates for common leopard Panthera pardus and clouded leopard Neofelis nebulosa in Manas National Park, Assam, India. Oryx 48:149-155. DOI: 10.1017/S0030605312000373. 
564 Brashares JS, Arcese P, \& Sam MK. 2001. Human demography and reserve size predict wildlife 565 extinction in West Africa. Proc. R. Soc. Lond. B 268:2473-2478. $566 \quad$ DOI:10.1098/rspb.2001.1815.

567 Broquet T, Petit E. 2004. Quantifying genotyping errors in noninvasive population genetics. 568 Molecular Ecology 13:3601-3608. DOI: 10.1111/j.1365-294X.2004.02352.x.

569 Chanchani P, Noon BR, Bailey LL, Warrier RA 2016. Conserving tigers in working $570 \quad$ landscapes. Conservation Biology, 30:649-660. DOI: 10.1111/cobi.12633.

571 Chauhan DS, Harihar A, Goyal SP, Qureshi, Q, Lal P, \& Mathur VB. 2005. Estimating leopard 572 population using camera traps in Sariska Tiger Reserve. Wildlife Institute of India, Dehra $573 \quad$ Dun, India, 23.

574

575

576

577

578

579

580

581

582

583

584

585

586

Cornuet JM \& Luikart G. 1996. Description and power analysis of two tests for detecting recent population bottlenecks from allele frequency data. Genetics 144: 2001-2014.

Dutta T, Sharma S, Maldonado JE, Wood TC, Panwar HS, Seidensticker J. 2013. Gene flow and demographic history of leopards (Panthera pardus) in the central Indian highlands. Evolutionary Applications 6:949-959. DOI: 10.1111/eva.12078.

Dutta T, Sharma S, Maldonado JE, Wood TC, Seidensticker J. 2012. A reliable method for individual identification and gender determination of wild leopards (Panthera pardus fusca) using non-invasive samples. Conservation Genetics Resources 4:665-667. DOI: 10.1007/s12686-012-9618-5.

Earl DA, vonHoldt BM. 2012. STRUCTURE HARVESTER: A website and program for visualizing STRUCTURE output and implementing the Evanno method. Conservation Genetics Resources 4:359-361. DOI: 10.1007/s12686-011-9548-7.

Estes JA, Terborgh J, Brashares JS, Power ME, Berger J, Bond WJ, Carpenter SR, Essington TE, 
587

588

589

590

591

592

593

594

595

596

597

598

599

600

601

602

603

604

605

606

607

608

609

Holt RD, Jackson JBC, Marquis RJ, Oksanen L, Oksanen T, Paine RT, Pikitch EK, Ripple WJ, Sandin SA, Scheffer M, Schoener TW, Shurin JB, Sinclair ARE, Soulé ME, Virtanen R, Wardle DA. 2011. Trophic Downgrading of Planet Earth. Science 333:301-306. DOI: 10.1126/science. 1205106.

Excoffier L, Laval G, Schneider S. 2005. Arlequin ver 3.1: An Integrated Software Package for Population Genetics Data Analysis. DOI: 10.1093/nq/s9-II.43.326-b.

Falush D, Stephens M, Pritchard JK. 2003. Inference of Population Structure Using Multilocus Genotype Data: Linked Loci and Correlated Allele Frequencies Daniel. JAMA: The Journal of the American Medical Association 164:1567-1587. DOI: 10.1001/jama.1987.03400040069013.

Farhadinia MS, Farahmand H, Gavashelishvili A, Kaboli M, Karami M, Khalili B, Montazamy S. 2015. Molecular and craniological analysis of leopard, Panthera pardus (Carnivora: Felidae) in Iran: Support for a monophyletic clade in Western Asia. Biol. J. Linn. Soc. 114:721-736. DOI: 10.1111/bij.12473.

Farhadinia MS, Johnson PJ, Macdonald DW, Hunter LT. 2018. Anchoring and adjusting amidst humans: Ranging behavior of Persian leopards along the Iran-Turkmenistan borderland. PloS one. 13:e0196602. DOI: 10.1371/journal.pone.0196602.

Frantz AC, McDevitt AD, Pope LC, Kochan J, Davison J, Clements CF, Elmeros M., MolinaVacas, G., Ruiz-Gonzalez, A., Balestrieri, A. and Van Den Berge, K. \& Van Den Berge, K. 2014. Revisiting the phylogeography and demography of European badgers (Meles meles) based on broad sampling, multiple markers and simulations. Heredity, 113:443.

Garza JC, Williamson EG. 2001. Detection of reduction in population size using data from microsatellite loci. Molecular Ecology 10:305-318. 
610 Gavashelishvili A, Lukarevskiy V. 2008. Modelling the habitat requirements of leopard 611 Panthera pardus in west and central Asia. Journal of Applied Ecology 45:579-588. DOI: 10.1111/j.1365-2664.2007.01432.x.

613 Goossens B, Chikhi L, Ancrenaz M, Lackman-Ancrenaz I, Andau P, Bruford MW. 2006. 614 Genetic Signature of Anthropogenic Population Collapse in Orang-utans. PLoS Biology 615 4:e25. DOI: 10.1371/journal.pbio.0040025.

616 Grant T. 2012. Leopard population density, home range size and movement patterns in a mixed 617 landuse area of the mangwe district of Zimbabwe. :1-143.

618 Harihar A, Pandav B, Goyal SP. 2009. Responses of tiger (Panthera tigris) and their prey to 619 removal of anthropogenic influences in Rajaji National Park, India. European Journal of $620 \quad$ Wildlife Research 55:97-105. DOI: 10.1007/s10344-008-0219-2.

621 Harihar A, Pandav B, Goyal SP. 2011. Responses of leopard Panthera pardus to the recovery of 622 a tiger Panthera tigris population. Journal of Applied Ecology 48:806-814. DOI: 623 10.1111/j.1365-2664.2011.01981.x.

624 Hines JE 2006. Program presence. See http://www. mbrpwrc. usgs. 625 gov/software/doc/presence/presence. $h$ tml

626 Ilani, G. 1981. The leopards of the Judean desert. Israel Land Nat, 6, 59-71.

627 Jacobson AP, Gerngross P, Lemeris Jr. JR, Schoonover RF, Anco C, Breitenmoser-Würsten C, 628 Durant SM, Farhadinia MS, Henschel P, Kamler JF, Laguardia A, Rostro-García S, Stein 629 AB, Dollar L. 2016. Leopard (Panthera pardus) status, distribution, and the research efforts $630 \quad$ across its range. PeerJ 4:e1974. DOI: 10.7717/peerj.1974.

631 Jhala YV, Qureshi Q, Gopal R. 2015. The status of tigers in india, 2014.

632 Johnsingh AJT, Ramesh K, Qureshi Q, A. D, Goyal SP, Rawat GS, Rajapandian K, Prasad S. 
633

634

635

636

637

638

639

640

641

642

643

644

645

646

647

648

649

650

651

652

653

2004. Conservation Status of Tiger and Associated Species in the Terai Arc Landscape, India.

Jombart T, Devillard S, Balloux F. 2010. Discriminant analysis of principal components: a new method for the analysis of genetically structured populations. BMC genetics, 11:94. DOI https://doi.org/10.1186/1471-2156-11-94.

Joshi PK, Roy PS, Singh S, Agrawal S, Yadav D. 2006. Vegetation cover mapping in India using multi-temporal IRS Wide Field Sensor (WiFS) data.Remote Sensing of Environment, 103:190-202.

Kalinowski ST. 2005. HP-RARE 1.0: a computer program for performing rarefaction on measures of allelic richness. Molecular ecology notes 5:187-189. DOI: 10.1111/j.14718286.2004.00845.x.

Kalinowski ST, Taper ML, Marshall TC. 2007. Revising how the computer program cervus accommodates genotyping error increases success in paternity assignment. Molecular Ecology 16:1099-1106. DOI: 10.1111/j.1365-294X.2007.03089.x.

Kalle R, Ramesh T, Qureshi Q, Sankar K. 2011. Density of tiger and leopard in a tropical deciduous forest of Mudumalai Tiger Reserve, southern India, as estimated using photographic capture-recapture sampling. Acta Theriologica 56:335-342. DOI: 10.1007/s13364-011-0038-9.

Karanth KK, Kudalkar S. 2017. History, location, and species matter: insights for humanwildlife conflict mitigation from India. Human dimensions of wildlife, 22:331-346. DOI: $10.1080 / 10871209.2017 .1334106$. 
654 Karanth KK, Nichols JD, Hines JE, Karanth KU, Christensen NL. 2009. Patterns and 655 determinants of mammal species occurrence in India. Journal of Applied Ecology 46:1189656 1200. DOI: $10.1111 / \mathrm{j} .1365-2664.2009 .01710 . x$.

657

658

659

660

661

662

663

664

665

666

667

668

669

670

671

672

673

674

675

676

Karanth KK, Nichols JD, Karanth KU, Hines JE, Christensen NL. 2010. The shrinking ark: patterns of large mammal extinctions in India. Proceedings of the Royal Society B: Biological Sciences 277:1971-1979. DOI: 10.1098/rspb.2010.0171.

Karanth KU, Sunquist M. 2000. Behavioural Correlates of Predation by Tiger (Panthera tigris) \& Leopard (Panthera pardus) in Nagarhole, India. The zoological society of London 4:255265.

Lorenzen ED, Nogués-Bravo D, Orlando L, Weinstock J, Binladen J, Marske KA, Ugan A, Borregaard MK, Gilbert MTP, Nielsen R, Ho SYW, Goebel T, Graf KE, Byers D, Stenderup JT, Rasmussen M, Campos PF, Leonard JA, Koepfli K-P, Froese D, Zazula G, Stafford TW, Aaris-Sørensen K, Batra P, Haywood AM, Singarayer JS, Valdes PJ, Boeskorov G, Burns JA, Davydov SP, Haile J, Jenkins DL, Kosintsev P, Kuznetsova T, Lai X, Martin LD, McDonald HG, Mol D, Meldgaard M, Munch K, Stephan E, Sablin M, Sommer RS, Sipko T, Scott E, Suchard MA, Tikhonov A, Willerslev R, Wayne RK, Cooper A, Hofreiter M, Sher A, Shapiro B, Rahbek C, Willerslev E. 2011. Species-specific responses of Late Quaternary megafauna to climate and humans. Nature 479:359-364. DOI: $10.1038 /$ nature 10574.

Maroju PA, Yadav S, Kolipakam V, Singh S, Qureshi Q, Jhala Y. 2016. Schrodinger's scat: a critical review of the currently available tiger (Panthera Tigris) and leopard (Panthera pardus) specific primers in India, and a novel leopard specific primer. BMC Genetics 17:37. DOI: $10.1186 / \mathrm{s} 12863-016-0344-\mathrm{y}$. 
677 Marsden CD, Woodroffe R, Mills MGL, Mcnutt JW, Creel S, Groom R, Emmanuel M, 678 Cleaveland S, Kat P, Rasmussen GSA, Ginsberg J, Lines R, Andre J-M, Begg C, Wayne 679 RK, Mable BK. 2012. Spatial and temporal patterns of neutral and adaptive genetic 680

681 variation in the endangered African wild dog (Lycaon pictus). Molecular Ecology 21:13791393. DOI: 10.1111/j.1365-294X.2012.05477.x.

682

683

684

685

686

687

688

689

690

691

692

693

694

695

696

697

698

699

Martinez-Cruz B, Godoy JA, Negro JJ. 2007. Population fragmentation leads to spatial and temporal genetic structure in the endangered Spanish imperial eagle. Molecular Ecology 16:477-486. DOI: 10.1111/j.1365-294X.2007.03147.x.

McManus JS, Dalton DL, Kotzé A, Smuts B, Dickman A, Marshal JP, Keith M. 2015. Gene flow and population structure of a solitary top carnivore in a human-dominated landscape. Ecology and evolution, 5:335-344. DOI: 10.1002/ece3.1322.

Miquel C, Bellemain E, Poillot C, Bessière J, Durand A, Taberlet P. 2006. Quality indexes to assess the reliability of genotypes in studies using noninvasive sampling and multiple-tube approach. Molecular Ecology Notes 6:985-988. DOI: 10.1111/j.1471-8286.2006.01413.x.

Mondal K, Sankar K, Qureshi Q, Gupta S, Chourasia P. 2012. Estimation of population and survivorship of leopard through photographic cature-recapture sampling in west india. World Journal of Zoology 7:30-39. DOI: 10.5829/idosi.wjz.2012.7.

Mondol S, Bruford MW, Ramakrishnan U. 2013. Demographic loss, genetic structure and the conservation implications for Indian tigers. Proceedings of the Royal Society B: Biological Sciences 280:20130496-20130496. DOI: 10.1098/rspb.2013.0496.

Mondol S, Karanth KU, Ramakrishnan U. 2009 (b). Why the Indian Subcontinent Holds the Key to Global Tiger Recovery. PLoS Genetics 5:e1000585. DOI: 10.1371/journal.pgen.1000585. 
700 Mondol S, Kumar NS, Gopalaswamy A, Sunagar K, Karanth KU, Ramakrishnan U. 2014.

701 Identifying species, sex and individual tigers and leopards in the Malenad-Mysore Tiger

702 Landscape, Western Ghats, India. Conservation Genetics Resources 7:353-361. DOI:

$703 \quad 10.1007 / \mathrm{s} 12686-014-0371-9$.

704 Mondol S, R Navya, Athreya V, Sunagar K, Selvaraj VM, Ramakrishnan U. 2009 (a). A panel of

705 microsatellites to individually identify leopards and its application to leopard monitoring in

706 human dominated landscapes. BMC Genetics 10:79. DOI: 10.1186/1471-2156-10-79.

707 Mondol S, Sridhar V, Yadav P, Gubbi S, Ramakrishnan U. 2015. Tracing the geographic origin

708 of traded leopard body parts in the indian subcontinent with DNA-based assignment tests.

709 Conservation Biology 29:556-564. DOI: 10.1111/cobi.12393.

710 Mora MS, Mapelli FJ, Gaggiotti OE, Kittlein MJ, Lessa EP. 2010. Dispersal and population

711 structure at different spatial scales in the subterranean rodent Ctenomys australis. BMC

712 Genetics 11:9. DOI: 10.1186/1471-2156-11-9.

713 Naha D, Sathyakumar S, Rawat GS. 2018. Understanding drivers of human-leopard conflicts in

714 the Indian Himalayan region: Spatio-temporal patterns of conflicts and perception of local

715 communities towards conserving large carnivores. PLOS ONE 13:e0204528. DOI:

$716 \quad$ 10.1371/journal.pone.0204528.

717 Nater A, Greminger MP, Arora N, van Schaik CP, Goossens B, Singleton I, Verschoor EJ,

718 Warren KS, Krützen M. 2015. Reconstructing the demographic history of orang-utans using

719 Approximate Bayesian Computation. Molecular Ecology. 24:310-327. DOI:

$720 \quad 10.1111 /$ mec. 13027.

721 Nei M. 1973. Analysis of gene diversity in subdivided populations. Proceedings of the National 722 Academy of Sciences, 70:3321-3323. 
723 Odden M, Athreya V, Rattan, S, Linnell JD. 2014. Adaptable neighbours: movement patterns of

724 GPS-collared leopards in human dominated landscapes in India. PLoS One, 9:e112044.

725 DOI: 10.1371/journal.pone.0112044.

726 Parks, SA, Harcourt AH. 2002. Reserve size, local human density, and mammalian extinctions in

727

728

729

730

731

732

733

734

735

736

737

738

739

740

741

742

743

744

745

U.S protected areas. Conservation Biology. 16:800-808. (10.1046/j. 15231739.2002.00288.x).

Paijmans JL, Barlow A, Förster DW, Henneberger K, Meyer M, Nickel B, Nagel D, Havmøller RW, Baryshnikov GF, Joger U, Rosendahl W. 2018. Historical biogeography of the leopard (Panthera pardus) and its extinct Eurasian populations. BMC evolutionary biology, 18:156. DOI: $10.1186 / \mathrm{s} 12862-018-1268-0$.

Pawar D, Nelson HP, Pawar DR, Khanwilkar S. 2019. Estimating Leopard Panthera pardus fusca (Mammalia: Carnivora: Felidae) abundance in Kuno Wildlife Sanctuary, Madhya Pradesh, India. Journal of Threatened Taxa, 11:13531-13544.

Peakall R, Smouse PE. 2012. GenAlEx 6.5: genetic analysis in Excel. Population genetic software for teaching and research--an update. Bioinformatics 28:2537-2539. DOI: 10.1093/bioinformatics/bts460.

Perez I, Geffen E, Mokady O. 2006. Critically Endangered Arabian leopards Panthera pardus nimr in Israel: estimating population parameters using molecular scatology. Oryx 40:295301. DOI: $10.1017 / \mathrm{S} 0030605306000846$.

Piry S, Alapetite A, Cornuet JM, Paetkau D, Baudouin L, Estoup A. 2004. GENECLASS2: A software for genetic assignment and first-generation migrant detection. Journal of Heredity 95:536-539. DOI: 10.1093/jhered/esh074.

Pritchard JK, Stephes M, Donnelly P. 2000. Inference of population structure using multilocus 

8286.2007.01758.x.

748

Rangarajan, M. 1999. Fencing the forest: conservation and ecological change in India's central provinces 1860-1914. Oxford University Press

Rangarajan M. 2001 India's wildlife history. New Delhi, India: Permanent Black.

Rangarajan M. 2005. India's wildlife history: an introduction. Orient Blackswan.

Raza RH, Chauhan DS, Pasha MKS, Sinha S. 2012. Illuminating the blind spot: A study on illegal trade in leopard parts in India (2001-2010). New Delhi: TRAFFIC India/WWF India. Ripple WJ, Estes JA, Beschta RL, Wilmers CC, Ritchie EG, Hebblewhite M, Berger J, Elmhagen B, Letnic M, Nelson MP, Schmitz OJ, Smith DW, Wallach AD, Wirsing AJ. 2014. Status and Ecological Effects of the World's Largest Carnivores. Science 343:1241484. DOI: 10.1126/science. 1241484 .

Ropiquet A, Knight AT, Born C, Martins Q, Balme GA, Kirkendall L, Hunter LTB, Senekal C, Matthee CA, 2015. Implications of spatial genetic patterns for conserving African leopards. Comptes Rendus Biologies 338:728-737. DOI: 10.1016/j.crvi.2015.06.019.

Roy PS, Joshi PK, Singh S, Agarwal S, Yadav D, Jegannathan C. 2006. Biome mapping in India using vegetation type map derived using temporal satellite data and environmental parameters. Ecological Modelling 197:148-158. DOI: 10.1016/j.ecolmodel.2006.02.045.

Schipper J, Chanson JS, Chiozza F, Cox NA, Hoffmann M, Katariya V, Lamoreux J, Rodrigues ASL, Stuart SN, Temple HJ. 2008. The status of the world's land and marine mammals: diversity, threat, and knowledge. Science, 322: 225-230.

Selvan KM, Lyngdoh S, Habib B, Gopi GV. 2014. Population density and abundance of sympatric large carnivores in the lowland tropical evergreen forest of Indian Eastern 
Himalayas. Mammalian Biology 79:254-258. DOI: 10.1016/j.mambio.2014.03.002.

770

771

772

773

774

775

776

777

778

779

780

781

782

783

784

785

786

787

788

789

790

791

Spong G, Johansson M, Bjorklund M. 2000. High genetic variation in leopards indicates large and long-term stable effective population size. Molecular Ecology 9:1773-1782. DOI: 10.1046/j.1365-294X.2000.01067.x.

Stein A, Athreya V, Balme G, Henschel P, Karanth U, Miquelle D. 2016. Panthera pardus, Leopard. The IUCN Red List of Threatened Species 2016: e. T15954A50659089.

Storz JF, Beaumont MA. 2002. Testing for Genetic Evidence of Population Expansion and Contraction: An Empirical Analysis of Microsatellite DNA Variation Using a Hierarchical Bayesian Model Published by: Society for the Study of Evolution Stable URL: http://www.jstor.org/stable/306. Evolution 56:154-166.

Sugimoto T, Gray TNE, Higashi S, Prum S. 2014. Examining genetic diversity and identifying polymorphic microsatellite markers for noninvasive genetic sampling of the Indochinese leopard (Panthera pardus delacouri). Mammalian Biology 79:406-408. DOI: 10.1016/j.mambio.2014.06.002.

Team RC. (2018). R Development Core Team. R: A language and environment for statistical computing. $R$ Foundation for Statistical Computing, Vienna, Austria; 2014. Google Scholar.

Thapa K, Shrestha R, Karki J, Thapa GJ, Subedi N, Pradhan NMB, Dhakal M, Khanal P, Kelly MJ. 2014. Leopard Panthera pardus fusca Density in the Seasonally Dry, Subtropical Forest in the Bhabhar of Terai Arc, Nepal. Advances in Ecology 2014:1-12. DOI: $10.1155 / 2014 / 286949$.

Uphyrkina O, Johnson WE, Quigley H, Miquelle D, Marker L, Bush M, O’Brien SJ. 2001. Phylogenetics, genome diversity and origin of modern leopard, Panthera 
pardus \ndoi:10.1046/j.0962-1083.2001.01350.x. Molecular Ecology 10:2617-2633.

793

794

795

796

797

798

799

800

801

802

803

804

805

806

807

808

809

810

811

Valdiosera CE, García-Garitagoitia JL, Garcia N, Doadrio I, Thomas MG, Hänni C, Arsuaga JL, Barnes I, Hofreiter M, Orlando L, Götherström A. 2008. Surprising migration and population size dynamics in ancient Iberian brown bears (Ursus arctos). Proceedings of the National Academy of Sciences 105:5123-5128. DOI: 10.1073/pnas.0712223105.

Valiere N. 2002. Gimlet: a computer program for analysing genetic individual identification data. Molecular Ecology Notes 2:377-379. DOI: 10.1046/j.1471-8286.2002.00228.x.

Van Oosterhout C, Hutchinson WF, Wills DPM, Shipley P. 2004. MICRO-CHECKER: software for identifying and correcting genotyping errors in microsatellite data. Molecular Ecology Notes 4:535-538. DOI: 10.1111/j.1471-8286.2004.00684.x.

Wang SW, Macdonald DW. 2009. The use of camera traps for estimating tiger and leopard populations in the high altitude mountains of Bhutan. Biological Conservation 142:606613. DOI: 10.1016/j.biocon.2008.11.023.

Wolf C, Ripple WJ. 2017. Range contractions of the world's large carnivores. Royal Society Open Science 4:170052. DOI: 10.1098/rsos.170052.

WPSI. 2017. Poaching statistics. Available from http://www.wpsiindia.org/statistics/leopard.php (accessed August 2019).

Zhu L, Zhan X, Wu H, Zhang S, Meng T, Bruford MW, Wei F. 2010. Conservation Implications of Drastic Reductions in the Smallest and Most Isolated Populations of Giant Pandas. Conservation Biology 24:1299-1306. DOI: 10.1111/j.1523-1739.2010.01499.x. 


\section{Table $\mathbf{1}$ (on next page)}

Table 1

Genetic diversity and genotyping error details for the leopard samples collected across TeraiArc landscape $(n=56)$ in this study. A total of 13 microsatellite loci were used. Data from these samples have been added to earlier leopard forensic data described in Mondol et al. (2014). 
Table 1: Genetic diversity and genotyping error details for the leopard samples collected across Terai Arc landscape ( $\mathrm{n}=56$ ) in this study. A total of 13 microsatellite loci were used. Data from these samples have been added to earlier leopard forensic data described in Mondol et al. (2014).

\begin{tabular}{|c|c|c|c|c|c|c|c|c|c|c|}
\hline Locus & $\begin{array}{l}\text { Repeat } \\
\text { length }\end{array}$ & $\mathbf{N}_{\mathbf{A}}$ & $\begin{array}{c}\text { Allelic size } \\
\text { range }\end{array}$ & $\mathbf{H}_{\mathbf{E}}$ & $\mathbf{H}_{\mathbf{O}}$ & Null Allele & $\begin{array}{c}\text { Allelic } \\
\text { dropout }\end{array}$ & False allele & HWE & Reference \\
\hline FCA230 & 2 & 16 & 44 & 0.87 & 0.69 & 0.18 & 0.001 & 0.005 & Yes & Menotti-Raymond et al. (1999) \\
\hline FCA309 & 2 & 17 & 42 & 0.85 & 0.70 & 0.22 & 0.004 & 0.004 & Yes & Menotti-Raymond et al. (1999) \\
\hline FCA232 & 2 & 15 & 36 & 0.83 & 0.68 & 0.19 & 0.007 & 0.013 & Yes & Menotti-Raymond et al. (1999) \\
\hline FCA090 & 2 & 16 & 34 & 0.87 & 0.66 & 0.30 & 0.007 & 0.002 & Yes & Menotti-Raymond et al. (1999) \\
\hline FCA052 & 2 & 14 & 32 & 0.85 & 0.77 & 0.19 & 0.004 & 0.006 & Yes & Menotti-Raymond et al. (1999) \\
\hline FCA672 & 2 & 20 & 40 & 0.87 & 0.74 & 0.05 & 0.0 & 0.001 & Yes & Menotti-Raymond et al. (1999) \\
\hline FCA279 & 2 & 16 & 30 & 0.88 & 0.76 & 0.08 & 0.001 & 0.003 & Yes & Menotti-Raymond et al. (1999) \\
\hline FCA126 & 2 & 16 & 32 & 0.89 & 0.70 & 0.36 & 0.004 & 0.001 & Yes & Menotti-Raymond et al. (1999) \\
\hline msFCA391 & 4 & 10 & 36 & 0.86 & 0.64 & 0.19 & 0.009 & 0.007 & Yes & Mondol et al. (2011) \\
\hline msHDZ170 & 2 & 13 & 42 & 0.83 & 0.53 & 0.30 & 0.002 & 0.002 & Yes & Mondol et al. (2011) \\
\hline msFCA441 & 4 & 12 & 52 & 0.82 & 0.52 & 0.23 & 0.006 & 0.003 & Yes & Mondol et al. (2011) \\
\hline msFCA506 & 2 & 19 & 56 & 0.89 & 0.69 & 0.25 & 0.008 & 0 & Yes & Mondol et al. (2011) \\
\hline msFCA453 & 4 & 7 & 32 & 0.68 & 0.61 & 0.25 & 0.006 & 0.007 & Yes & Mondol et al. (2011) \\
\hline Mean (SD) & & $\begin{array}{l}14.69 \\
(3.41)\end{array}$ & $\begin{array}{l}39.08 \\
(7.71)\end{array}$ & $\begin{array}{c}0.84 \\
(0.05)\end{array}$ & $\begin{array}{c}0.67 \\
(0.07)\end{array}$ & 0.21 & 0.005 & 0.004 & & \\
\hline
\end{tabular}

$\mathrm{N}_{\mathrm{A}}$ - No. of alleles, $\mathrm{H}_{\mathrm{E}}$ - Expected heterozygosity, $\mathrm{H}_{\mathrm{O}}$ - Observed heterozygosity, HWE - Hardy-Weinberg Equilibrium 


\section{Table 2 (on next page)}

Table 2

Genetic differentiation (pairwise Fst and Gst) for four leopard subpopulations in the Indian subcontinent. The upper diagnonal presents the pairwise Gst values whereas the lower diagnonal presents the pairwise Fst values. 
Table 2: Genetic differentiation (pairwise $F_{s t}$ and $G_{s t}$ ) for four leopard subpopulations in the Indian subcontinent. The upper diagonal presents the pairwise $\mathrm{G}_{\text {st }}$ values whereas the lower diagonal presents the pairwise $\mathrm{F}_{\text {st }}$ values.

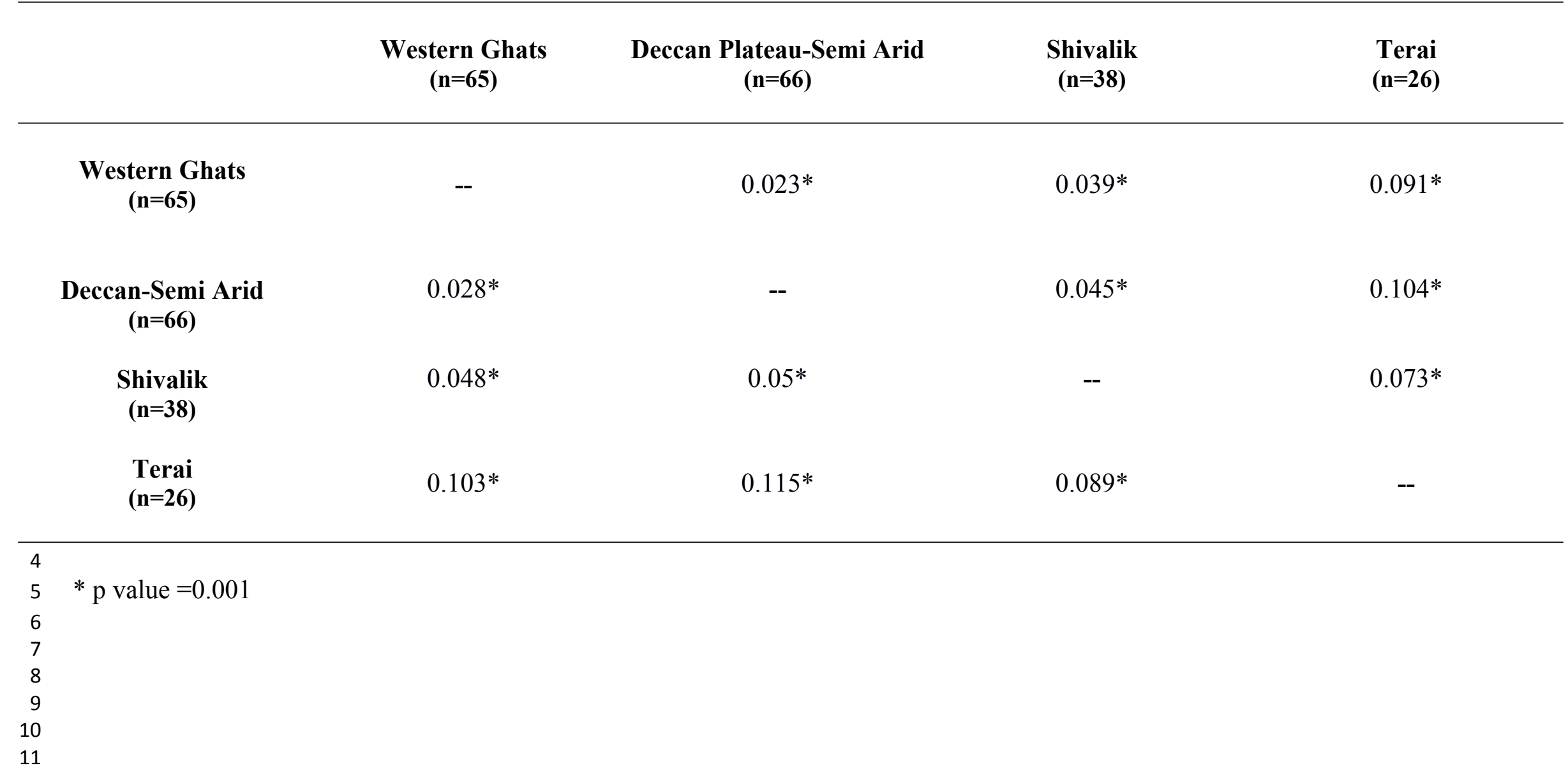




\section{Table 3(on next page)}

Table 3

Subpopulation-wise summary statistics (based on 13 microsatellite loci) for Indian leopards. 


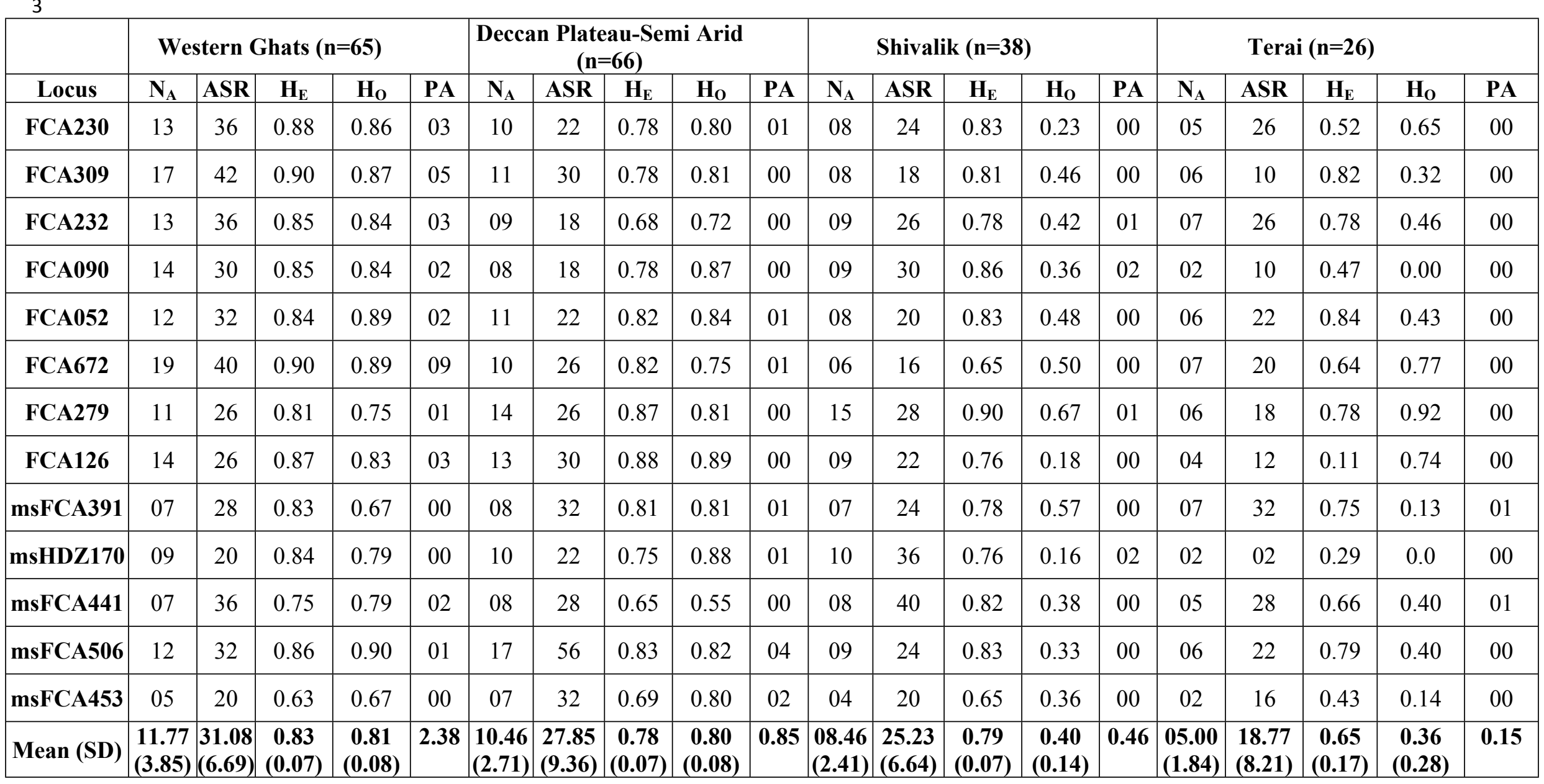

$5 \quad \mathrm{~N}_{\mathrm{A}}$ - No. of alleles, ASR- Allelic size range, $\mathrm{H}_{\mathrm{E}}-$ Expected heterozygosity, $\mathrm{H}_{\mathrm{O}}-$ Observed heterozygosity, PA- Private alleles 


\section{Table 4 (on next page)}

\section{Table 4}

Comparison of different demographic decline analyses results for different subpopulations of leopards across India. 
1

2 Table 4: Comparison of different demographic decline analyses results for different subpopulations of leopards across India.

\begin{tabular}{|c|c|c|c|c|c|c|}
\hline \multirow{2}{*}{ Method } & \multirow{2}{*}{ Analysis type } & \multicolumn{5}{|c|}{ Demographic signal } \\
\hline & & Model & Western Ghats & $\begin{array}{c}\text { Deccan Plateau-Semi } \\
\text { Arid } \\
\end{array}$ & Shivalik & Terai \\
\hline \multirow{3}{*}{ Bottleneck } & \multirow{4}{*}{ Qualitative } & IAM & $\begin{array}{l}\text { Heterogygosity excess } \\
\text { for } 13 \text { loci }\end{array}$ & $\begin{array}{l}\text { Heterogygosity excess } \\
\text { for } 10 \text { loci }\end{array}$ & $\begin{array}{l}\text { Heterogygosity excess } \\
\text { for } 12 \text { loci }\end{array}$ & $\begin{array}{l}\text { Heterogygosity excess } \\
\text { for } 11 \text { loci }\end{array}$ \\
\hline & & SMM & $\begin{array}{l}\text { Heterogygosity excess } \\
\text { for } 01 \text { loci }\end{array}$ & $\begin{array}{l}\text { Heterogygosity excess } \\
\text { for } 02 \text { loci }\end{array}$ & $\begin{array}{l}\text { Heterogygosity excess } \\
\text { for } 06 \text { loci }\end{array}$ & $\begin{array}{l}\text { Heterogygosity excess } \\
\text { for } 08 \text { loci }\end{array}$ \\
\hline & & ТPM & $\begin{array}{l}\text { Heterogygosity excess } \\
\text { for } 07 \text { loci }\end{array}$ & $\begin{array}{l}\text { Heterogygosity excess } \\
\text { for } 07 \text { loci }\end{array}$ & $\begin{array}{l}\text { Heterogygosity excess } \\
\text { for } 09 \text { loci }\end{array}$ & $\begin{array}{c}\text { Heterogygosity excess } \\
\text { for } 10 \text { loci }\end{array}$ \\
\hline M ratio & & & 0.37 (SD 0.09) & 0.38 (SD 0.09) & $0.33(\mathrm{SD} 0.09)$ & $0.29(\mathrm{SD} 0.15)$ \\
\hline $\begin{array}{l}\text { Storz-Beaumont } \\
\text { method }\end{array}$ & Quantitative & & $\begin{array}{c}\text { Decline- } 75 \% \\
\text { Time- } 200 \text { years ago }\end{array}$ & $\begin{array}{c}\text { Decline- } 90 \% \\
\text { Time- } \sim 125 \text { years ago }\end{array}$ & $\begin{array}{c}\text { Decline- } 90 \% \\
\text { Time- } \sim 125 \text { years ago }\end{array}$ & $\begin{array}{c}\text { Decline- } 88 \% \\
\text { Time- } \sim 120 \text { years ago }\end{array}$ \\
\hline $\begin{array}{l}\text { Extinction } \\
\text { Probability }\end{array}$ & Quantitative & Occupancy & 0.17 & 0.21 & & \\
\hline
\end{tabular}

4 
Figure 1

Figure 1

Genetic sampling and leopard population structure across the Indian subcontinent with forest cover map and leopard sampling locations used in this study. The map also shows the inferred biogeographic leopard habitats based on genetic structure, as found in this study and corroborative leopard genetic clusters indicated by program STRUCTURE (based on 13 microsatellite loci).

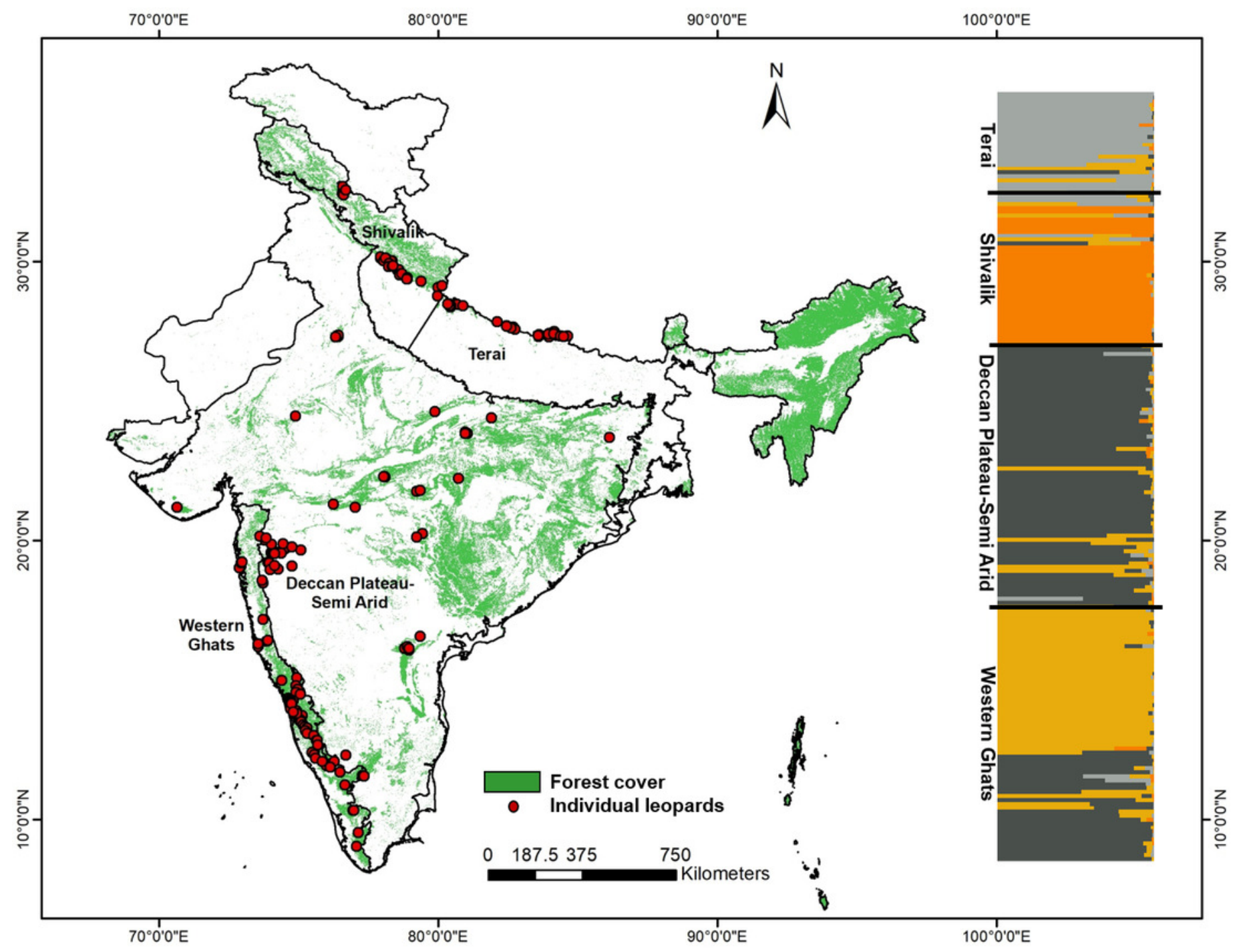




\section{Figure 2}

Figure 2

Demographic history of Indian leopards (Panthera pardus fusca). The left panel (figures A, C, $E$ and $G$ ) shows the posterior distributions for leopard population size changes for different subpopulations, based on 13 microsatellite loci using Storz and Beaumont approach. The dashed and solid lines represent posterior distributions of ancestral and present effective population sizes. The priors are represented by the dotted line. The right panel (figures B, D, $\mathrm{F}$, and $\mathrm{H}$ ) represents the posterior distribution for the time since the leopard population decline started for corresponding subpopulations. The priors are shown by the dotted lines. 

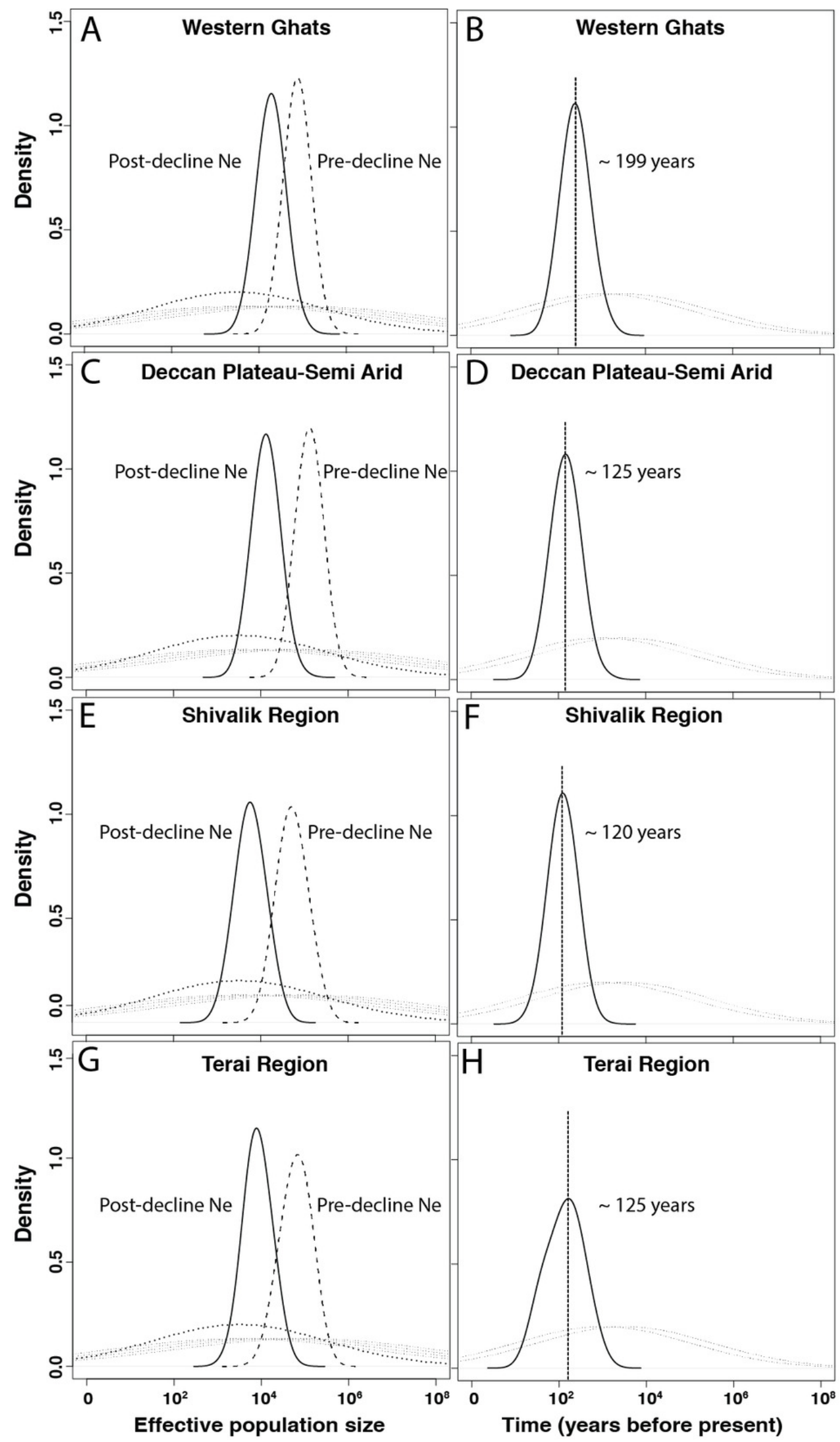

Peer] reviewing PDF | (2019:09:40994:1:1:NEW 24 Dec 2019) 


\section{Figure 3}

Figure 3

Patterns of leopard occurrence in India based on the analysis of questionnaire surveys. The map shows a gradient of estimated cell-wise occupancy probabilities created through spatial kriging. 


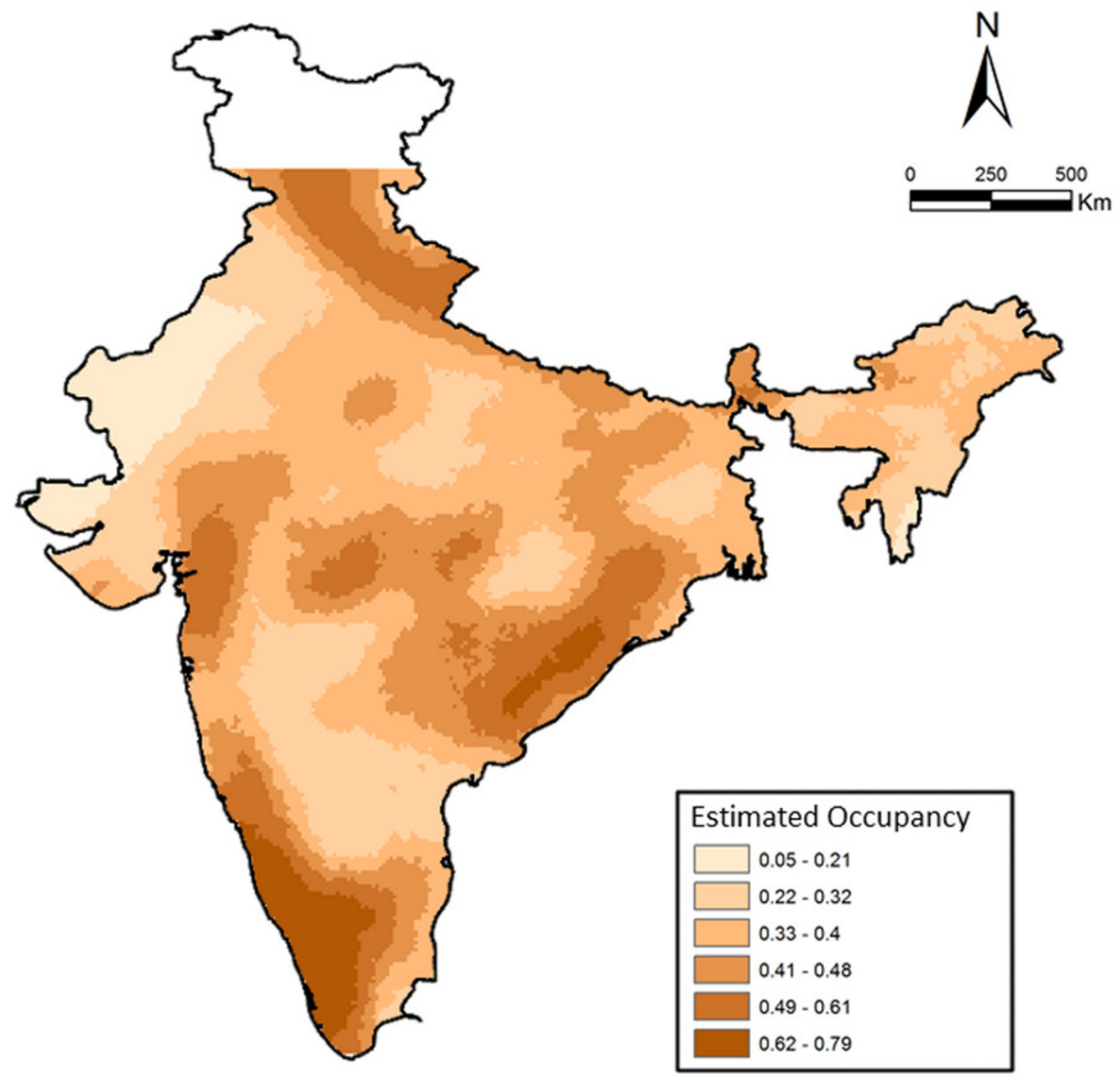

